\title{
A 15 años de la segunda desaparición de Jorge Julio López. Movilizaciones, actos y homenajes para mantener viva su memoria y exigir justicia
}

\author{
Pamela Dubois \\ pamela.sdubois@gmail.com \\ Facultad de Artes. Universidad Nacional de La Plata, Argentina \\ Facultad de Humanidades y Ciencias de la Educación. \\ Universidad Nacional de La Plata, Argentina
}

\section{María Emilia Nieto}

mariaemilianieto@gmail.com

Instituto de Investigaciones en Humanidades y Ciencias Sociales.

Universidad Nacional de La Plata, Argentina

CONICET, Argentina

\author{
Cita sugerida: Dubois, P. y Nieto, M. E. (2021). A 15 \\ años de la segunda desaparición de Jorge Julio López \\ Movilizaciones, actos y homenajes para mantener viva \\ su memoria y exigir justicia. Aletheia, 12(23), e112. \\ https://doi.org/10.24215/18533701e112
}

El pasado 18 de septiembre se realizaron diferentes actividades en la ciudad de La Plata y la marcha para exigir por memoria, verdad y justicia, al cumplirse 15 años de la segunda desaparición de Jorge Julio López, en el marco del juicio contra el represor Miguel Etchecolatz.

Jorge Julio López nació en General Villegas el 25 de noviembre de 1929. Llegó a Los Hornos en el año 1956 donde comenzó a trabajar como quintero y luego como albañil. Se casó con Irene Savegnago con quien tuvo dos hijos, Rubén y Gustavo. En los años '70 comenzó su militancia en la Unidad Básica "Juan Pablo Maestre", en Los Hornos. Por su compromiso militante fue secuestrado en su casa el 27 de octubre de 1976 junto con otros compañeros y permaneció en diferentes centros clandestinos de detención, tortura y exterminio del circuito represivo Camps, hasta el 4 de abril de 1977, cuando fue puesto a disposición del Poder Ejecutivo 
Nacional y trasladado a la Unidad Penitenciaria No 9, donde permaneció detenido hasta el 25 de junio de 1979.

En el año 1999 declaró por primera vez en los Juicios por la Verdad, aportando significativamente a la reconstrucción de los lugares que funcionaron en La Plata como centros clandestinos de detención, fundamentalmente del CCDTyE de Arana y Comisaría 5ta. El 28 de junio del año 2006 López brindó su testimonio en el marco del juicio contra Miguel Osvaldo Etchecolatz, quien era Director de Investigaciones de la Policía bonaerense y mano derecha del ex general Ramón Camps, cuando fue detenido ilegalmente por primera vez. El testimonio de López fue fundamental para condenar al represor por crímenes de lesa humanidad. El 18 de septiembre de 2006, día que tenía previsto presenciar los alegatos contra su propio torturador, se produjo su segunda desaparición. 15 años después, la causa judicial que la investiga, no tiene imputados ni registra avances significativos en el esclarecimiento de lo ocurrido.

Estos sucesos han dado lugar a numerosas reflexiones, debates, y luchas activas que se inscriben y materializan en la esfera pública en una multiplicidad de acciones. En este contexto, y con motivo de los 15 años de la segunda desaparición de Jorge Julio López, se realizaron el pasado 18 de septiembre en las ciudades de La Plata, Berisso y Ensenada, una serie de actividades, inauguradas el viernes 17 con una Video Intervención realizada por la Comisión Provincial por la Memoria, la Universidad Nacional de La Plata y el Programa de Apoyo a Juicios. La jornada consistió en la proyección, sobre la fachada de la casa de la CPM, del testimonio completo que Jorge Julio López brindó durante el juicio a Etchecolatz. La vigilia fue transmitida a partir de las 22 hs. del día viernes por Radio Futura, y finalizó a las 8 de la mañana del sábado, cuando se destapó una gigantografía, con la imagen de López y la leyenda "Jorge Julio López 15 años de impunidad. ¿Dónde está?”.

\section{IMAGEN 1}

Proyección del testimonio de Jorge Julio López en la fachada de la CPM.

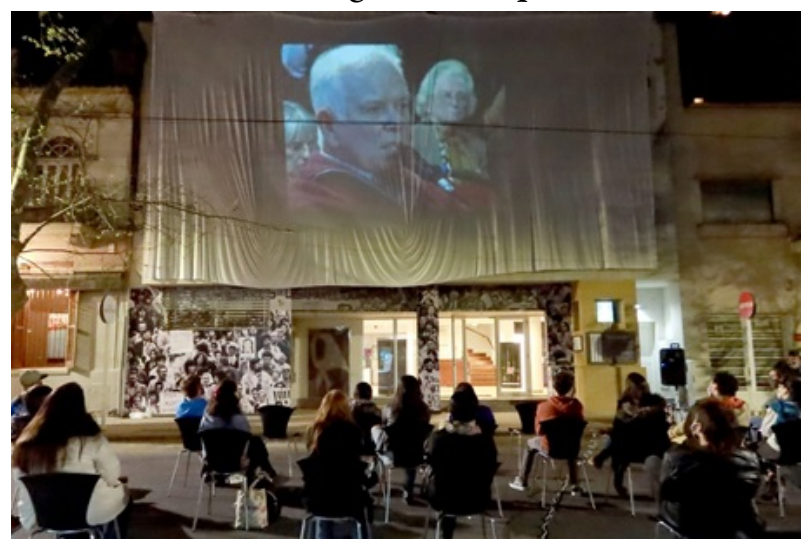

Fotografía: Gabriela B. Hernández (GbH Sur fotografía) ${ }^{1}$ 


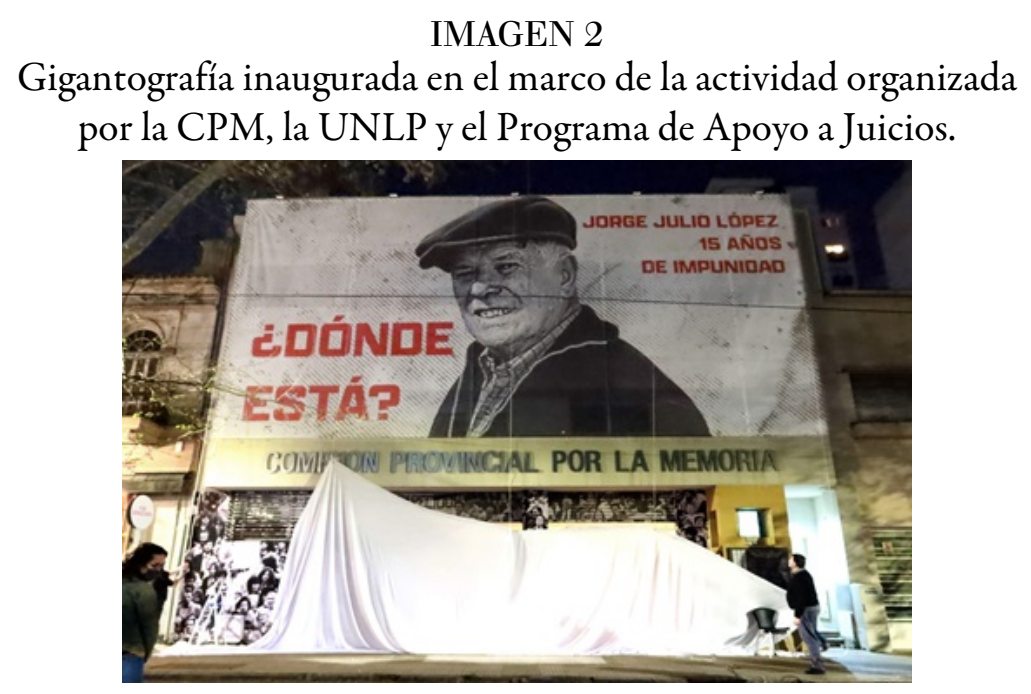

Fotografía: Gabriela B. Hernández (GbH Sur fotografía)

Ese mismo día, y como cada año, también se actualizó el número del mural emplazado en la fachada del edificio Sergio Karakachoff, ubicado en la esquina de avenida 7 y 48, en pleno centro de la ciudad de La Plata. Este mural, realizado por diferentes organizaciones políticas y sociales en el año 2008, se convirtió en una marca de memoria icónica de nuestra ciudad, que interpela el espacio público con la pregunta ¿A qué te podés acostumbrar?.

IMÁGENES 3 Y 4

Cambio de número del mural emplazado en el edificio Sergio Karakachoff.

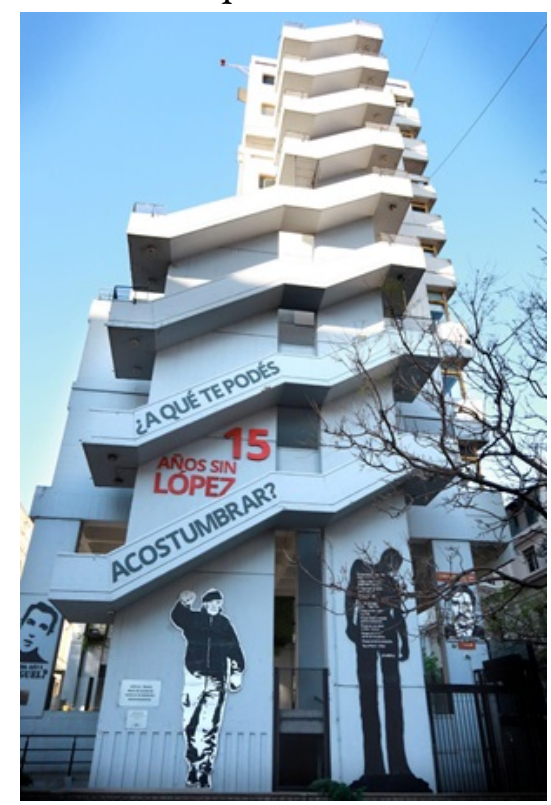




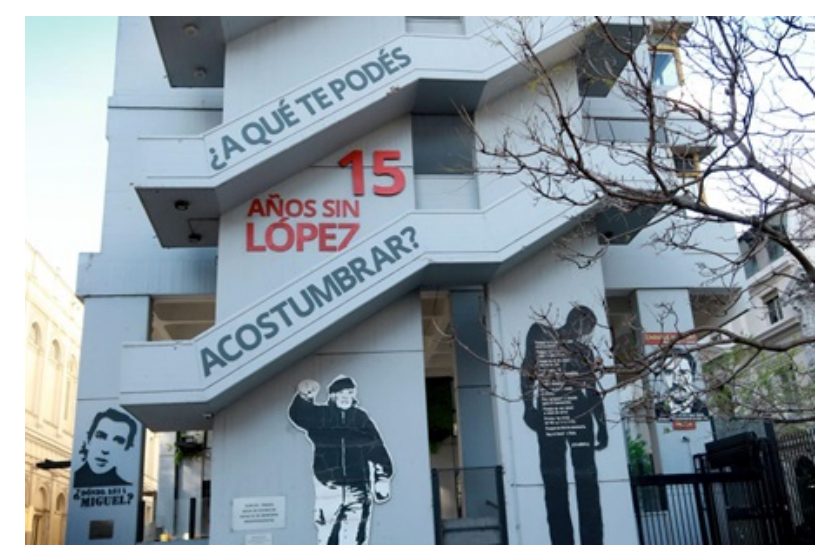

Fotografías:Gabriela B. Hernández (GbH Sur fotografía)

El sábado 18 las actividades comenzaron temprano. Por la mañana, el Espacio para la Memoria Ex Comisaría 5ta, realizó un encuentro, con aforo reducido, en el que estuvieron presentes Rubén López -hijo de Jorge-, la fotógrafa Helen Zout, Pastor Azuaje -compañero de militancia, a quien López le encomendó sus escritos y dibujos-, y Leonardo Fosatti - coordinador del sitio-. En el marco de la jornada, se destapó el icónico retrato de López, perteneciente a la serie fotográfica Huellas de desapariciones, que realizó Helen Zout entre los años 2000-2006. Esta imagen acompañará de forma permanente el ingreso al espacio.

IMÁGENES 5 Y 6

Encuentro Espacio Memoria Ex Comisaría 5ta.

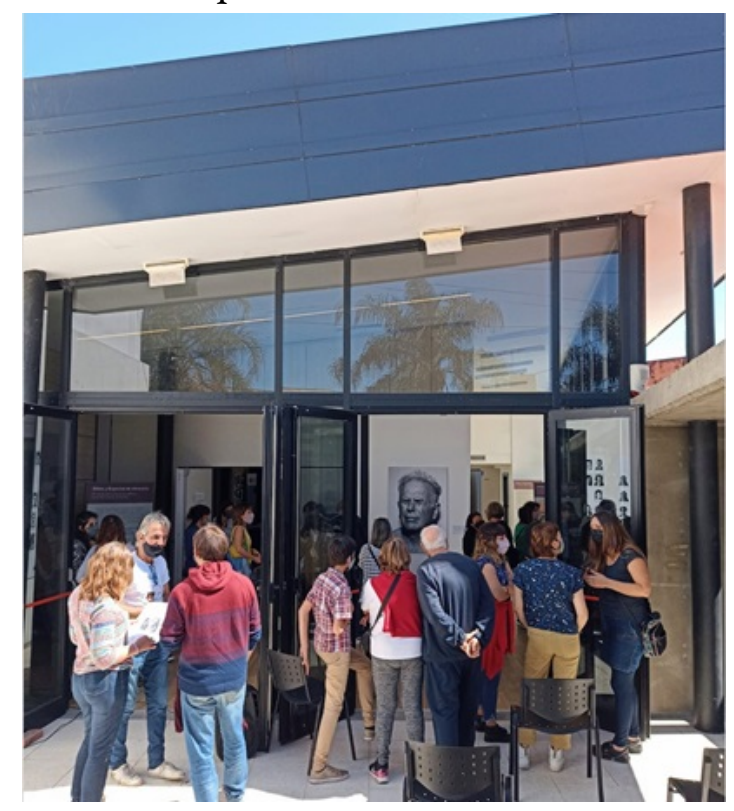




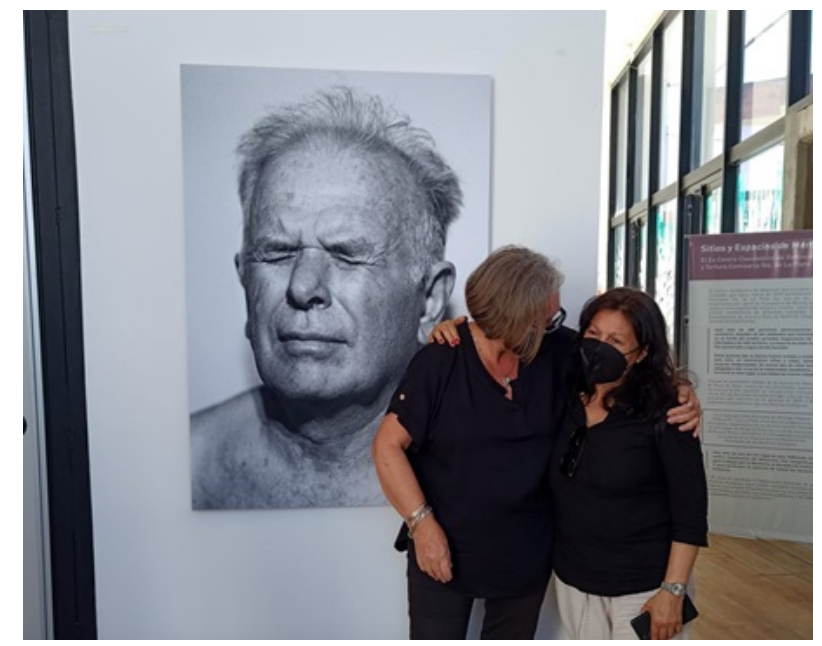

Fotos recuperadas de su página de facebook: https://www.facebook.com/Espaci oMemoriaExComisaria5ta/photos/pcb.931582794459495/931573377793770

Hacia las 13 horas, se llevó a cabo en la esquina de las calles 8 y 51, frente a la sede de los Tribunales Federales de La Plata, una actividad convocada por la Mesa por los Derechos Humanos de La Plata, que contó con la presencia de Rubén López y representantes de ADULP, FULP, la Secretaría de Derechos Humanos de la Nación y el Frente de Todos. Esta actividad consistió en la intervención de una escultura que fue realizada hace algunos años por los trabajadores de Astilleros Río Santiago, e inaugurada en el año 2018. Para su construcción se utilizaron materiales de trabajo del astillero, como destacó Rubén. El uso del calado para plasmar el retrato de López, genera la proyección de la imagen en el suelo. Este recurso de la silueta ha sido ampliamente utilizado en la Argentina para representar la desaparición de personas. Concretamente, la actividad propuesta el día 18, consistió en la colocación de una placa sobre esta escultura, en la que se lee "A 15 años de su segunda desaparición Jorge Julio López sigue dando testimonio. ¿Dónde está López?" Memoria, Verdad y Justicia.

\section{IMAGEN 7}

Rubén López junto a la escultura y placa inauguradas.

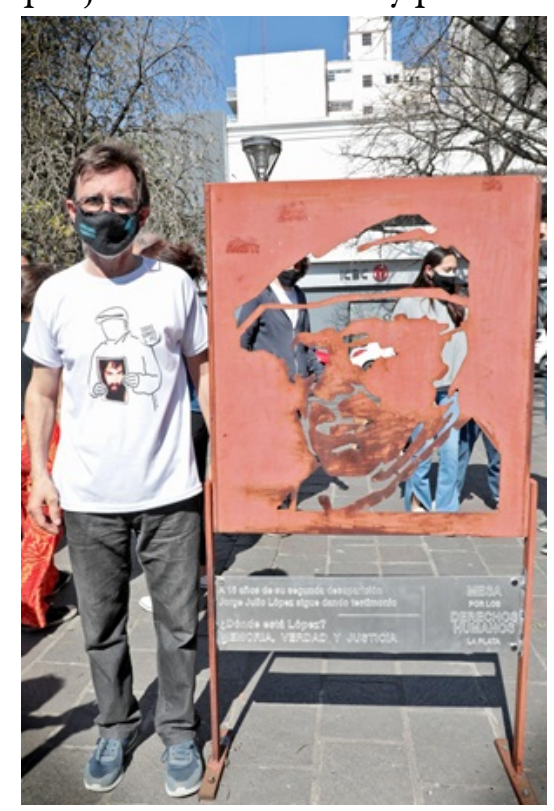




\section{IMAGEN 8}

Cierre de la actividad.

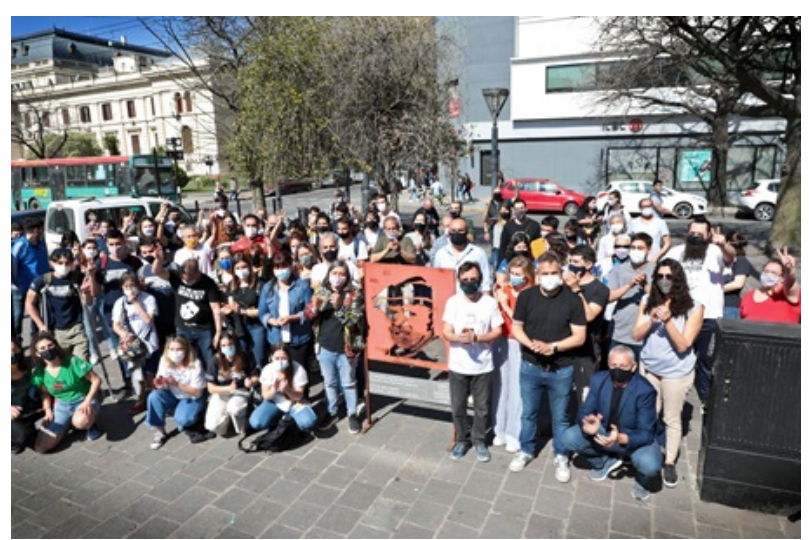

Fotografía: Gabriela B. Hernández (GbH Sur fotografía)

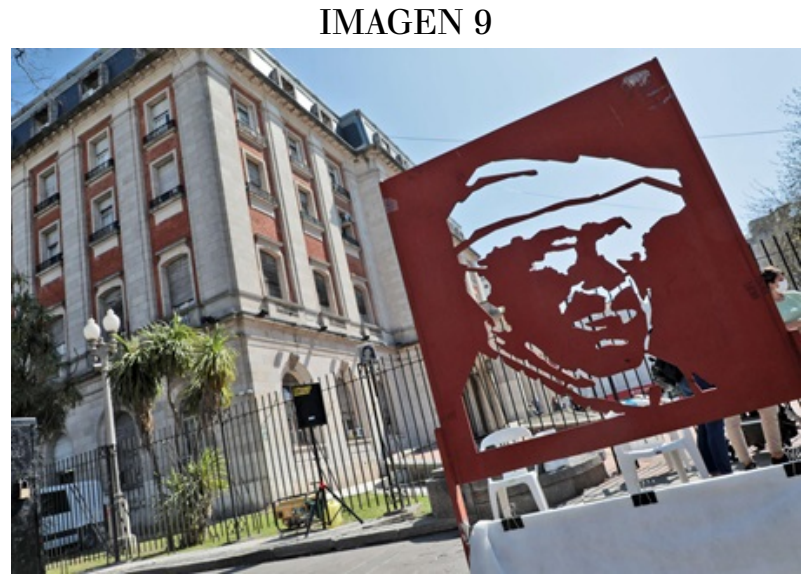

Fotografía: Gabriela B. Hernández (GbH Sur fotografía)

IMAGEN 10

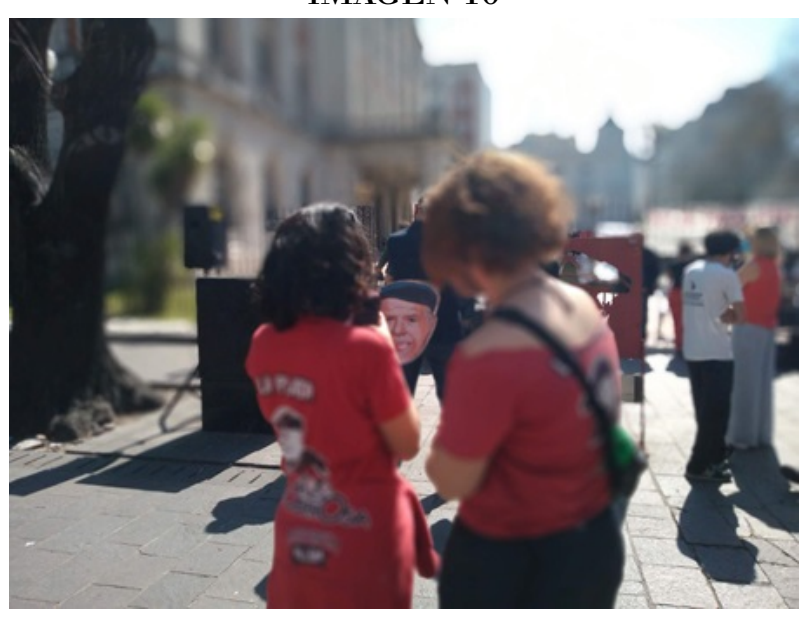

Fotografía: María Emilia Nieto 


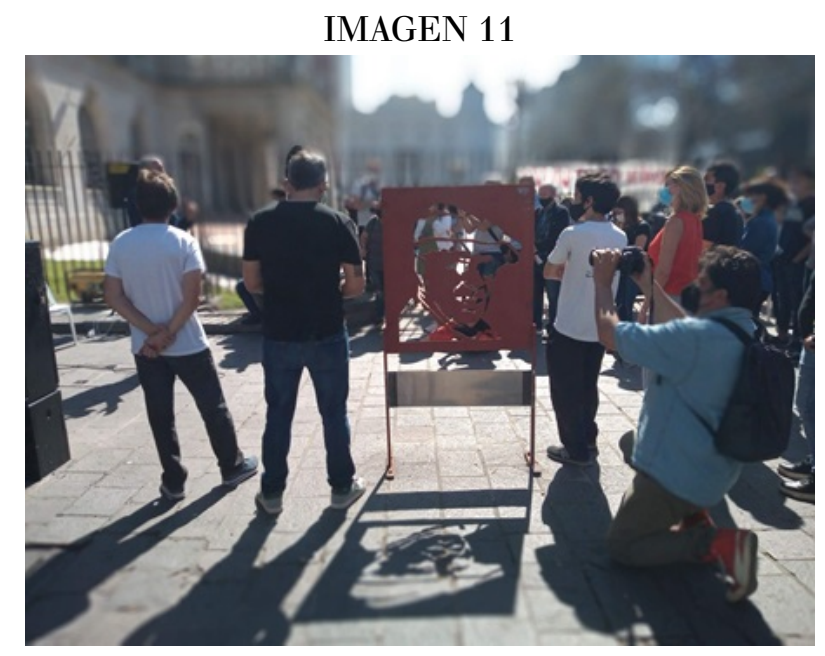

Fotografía: María Emilia Nieto

Hacia las 15 hs. comenzó la marcha convocada por la Multisectorial La Plata, Berisso y Ensenada, bajo la consigna "Pasan los gobiernos, continua la impunidad. Juicio y castigo a los responsables". El punto de encuentro como cada año fue Plaza Moreno y la movilización culminó en Plaza San Martín, haciendo escala en los Tribunales de 8 y 51 , donde se dijeron algunas palabras, antes de los discursos de cierre. La marcha contó con la participación de diferentes organizaciones sociales y políticas, y organismos de Derechos Humanos, como Hijas La Plata-Ensenada, La Asociación de Ex Detenidos Desaparecidos, el Espacio de lucha Nilda Eloy, quienes encabezaron la movilización.

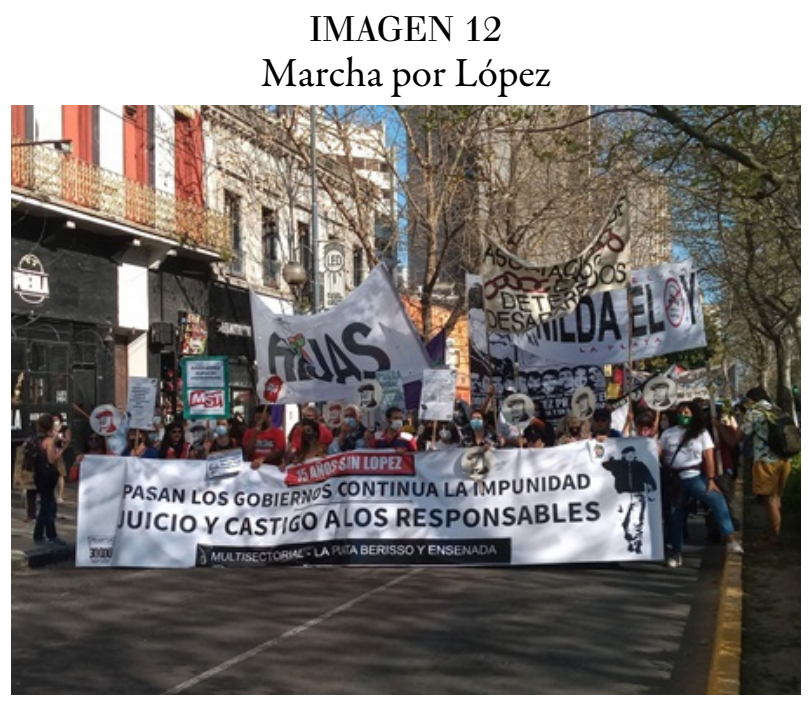

Fotografía: María Emilia Nieto 


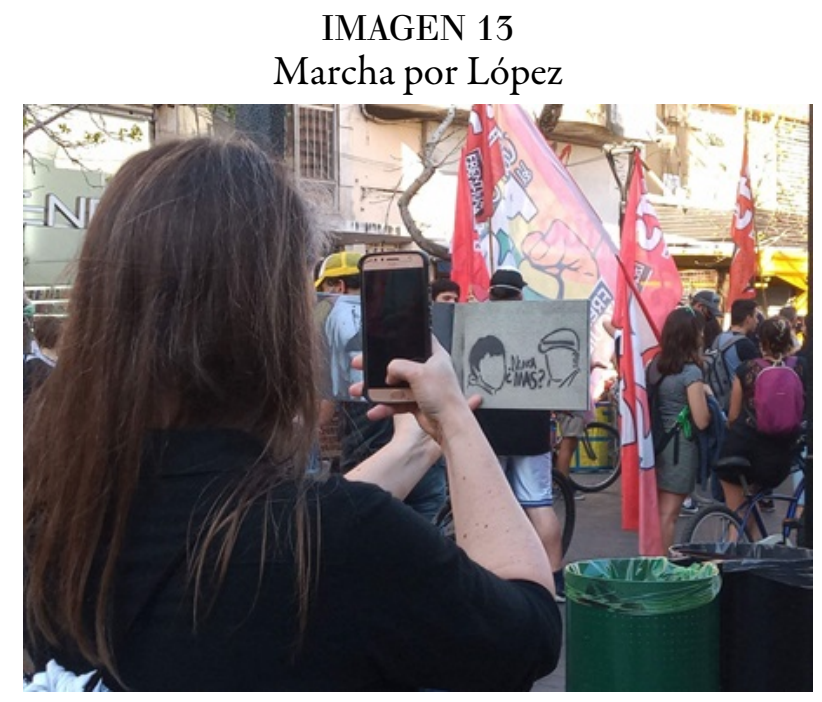

Fotografía: María Emilia Nieto

IMAGEN 14

Marcha por López

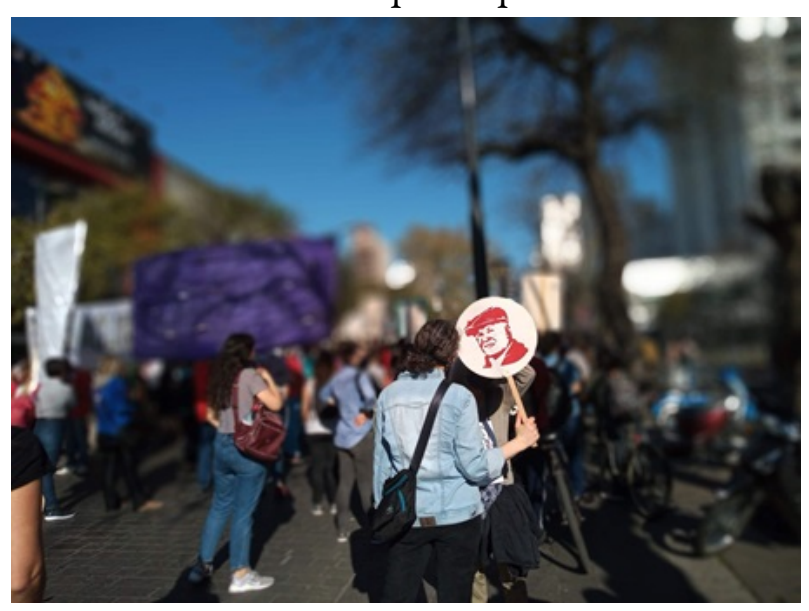

Fotografía: María Emilia Nieto

IMAGEN 15

Marcha por López

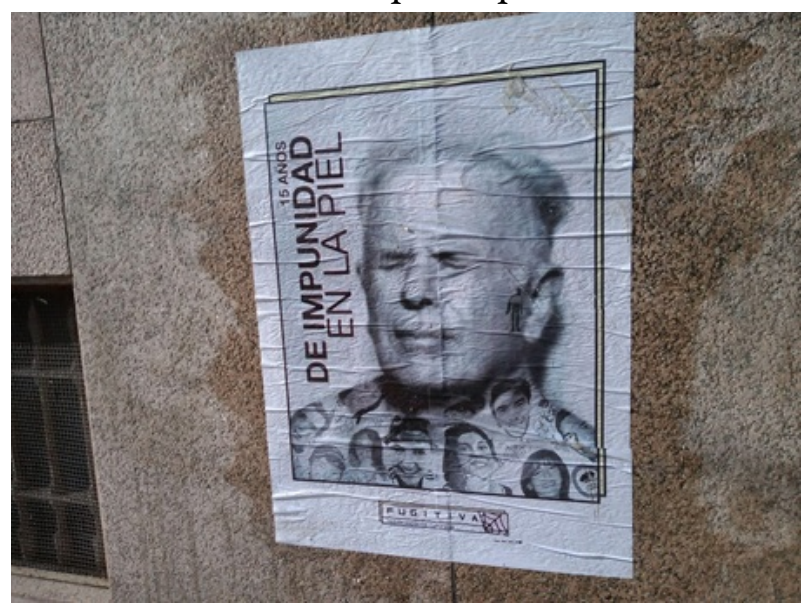

Afiche realizado por Fugitiva - Red de espacios culturales Adricola Terrestre Fotografía: María Emilia Nieto 


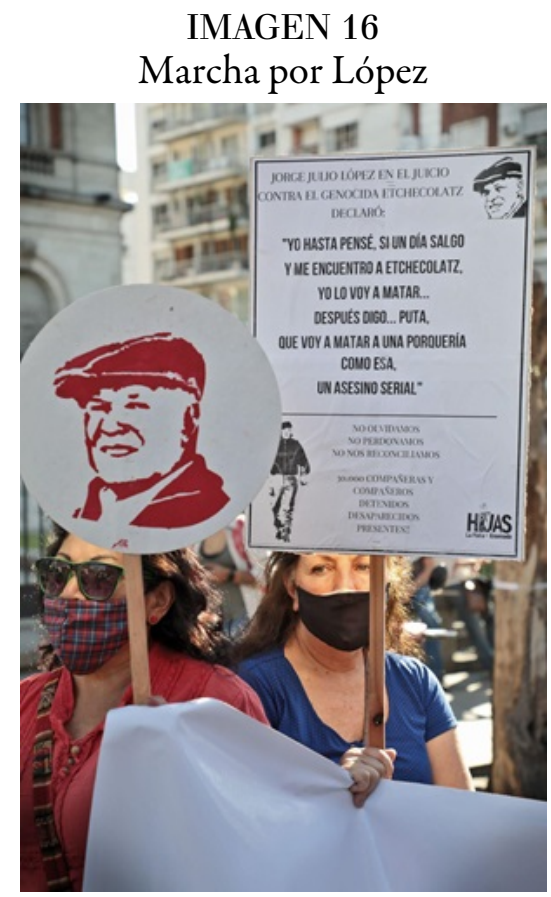

Fotografía: (GbH Sur fotografía)

IMAGEN 17

Marcha por López

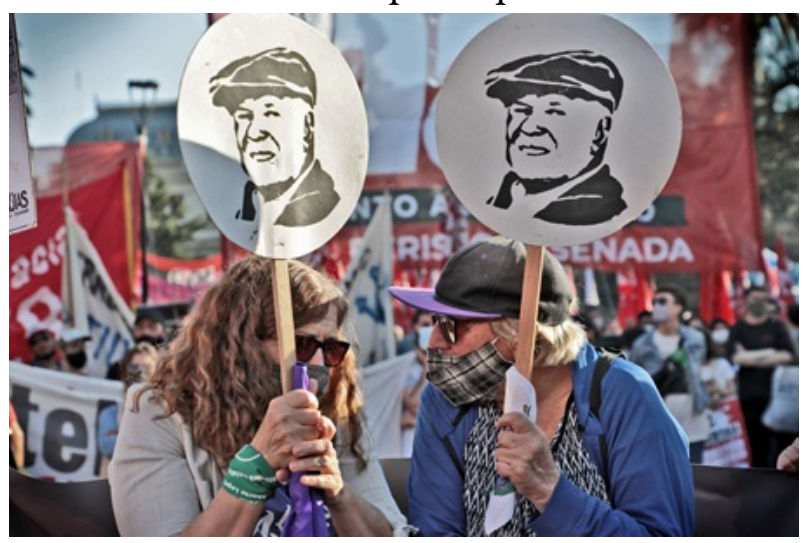

Fotografía: Gabriela B. Hernández (GbH Sur fotografía).

IMAGEN 18

Marcha por López

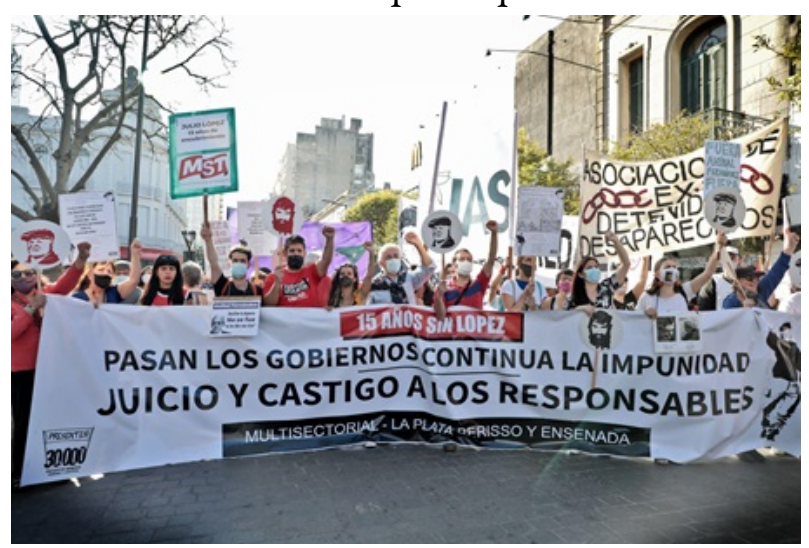

Fotografía: Gabriela B. Hernández (GbH Sur fotografía) 
IMAGEN 19

Marcha por López. Cierre y lectura de documento en Plaza San Martín

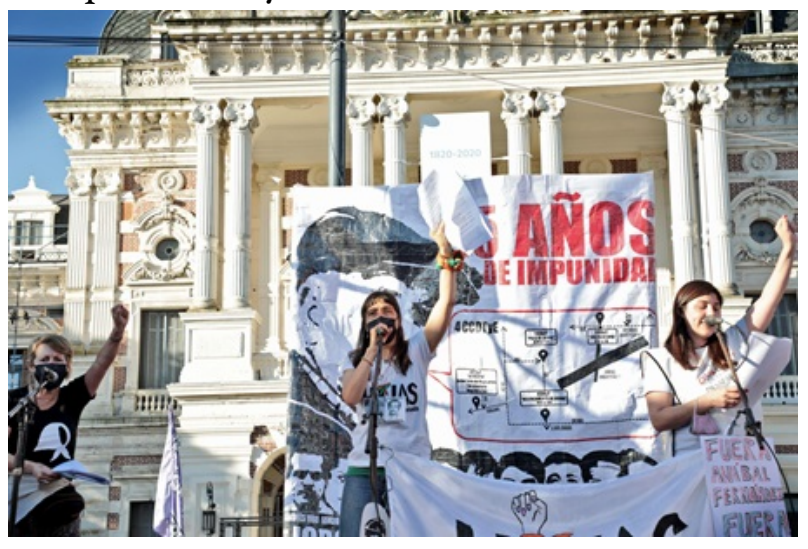

Fotografía: Gabriela B. Hernández (GbH Sur fotografía)

Durante la tarde del día 18, la agrupación H.I.J.@.S. Berisso y otras agrupaciones, inauguraron en la esquina de la Avenida Montevideo y la calle 8, un mural conmemorativo emplazado sobre una de las paredes laterales del Honorable Consejo Deliberante. El mismo fue realizado por Gerardo Luis Pacheco y Elba Eleodora Molinelli, quienes propusieron pensar cada trazo como un homenaje. Las diferentes escenas que se representan en el mural, se anclan, al tiempo en que materializan, la consigna Memoria-Verdad-Justicia.

IMAGEN 20

Mural realizado por HIJOS de Berisso

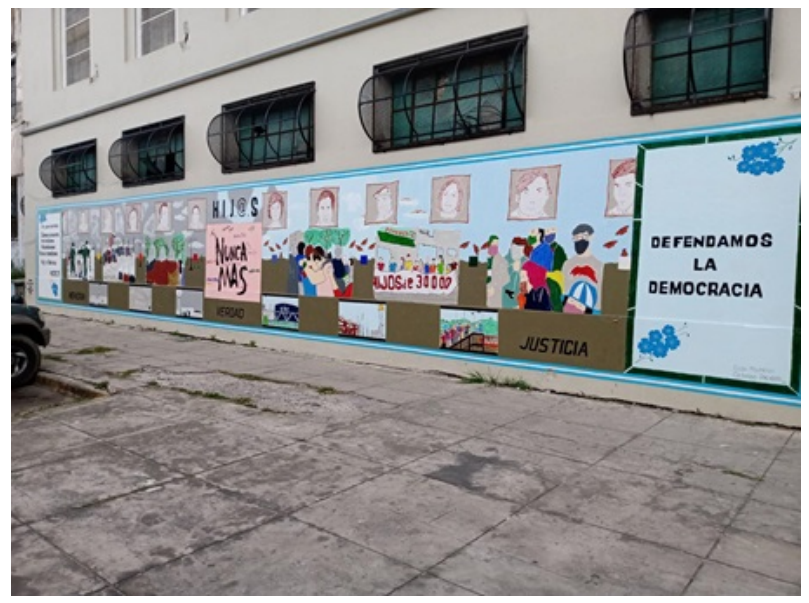

Fotografía: Pamela Dubois 


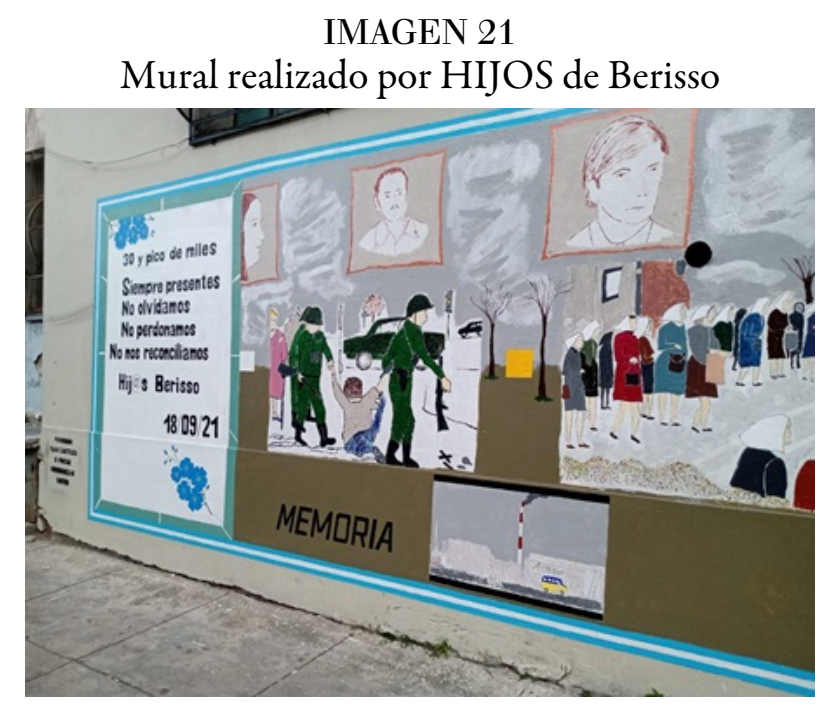

Fotografía: Pamela Dubois

\section{IMAGEN 22}

Mural realizado por HIJOS de Berisso

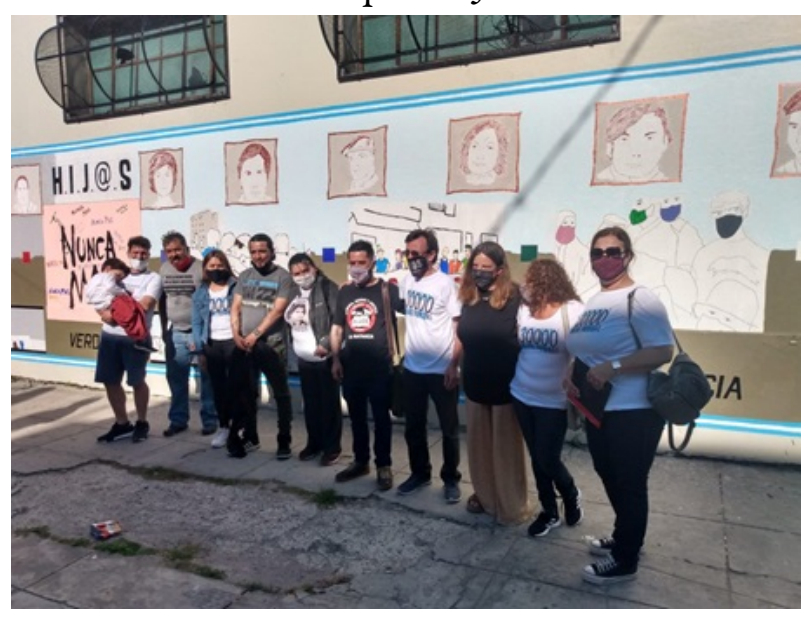

Fotografía recuperada de: Info Berisso https://infoberisso.com.ar/mur al-por-la-memoria-a-15-anos-de-la-segunda-desaparicion-de-julio-lopez

A pocos días de las actividades desarrolladas por los 15 años de la segunda desaparición de Jorge Julio López, el 23 de septiembre a las 15 hs., se realizó un acto homenaje en la plaza Jorge Julio López, ubicada en el barrio Villa del Plata en la localidad de Ensenada. Participaron en este encuentro, integrantes del programa Envión de Ensenada y Berisso, Rubén López, miembros de la mesa de familiares y sobrevivientes de Ensenada y la comparsa Halcones de Punta Lara. 

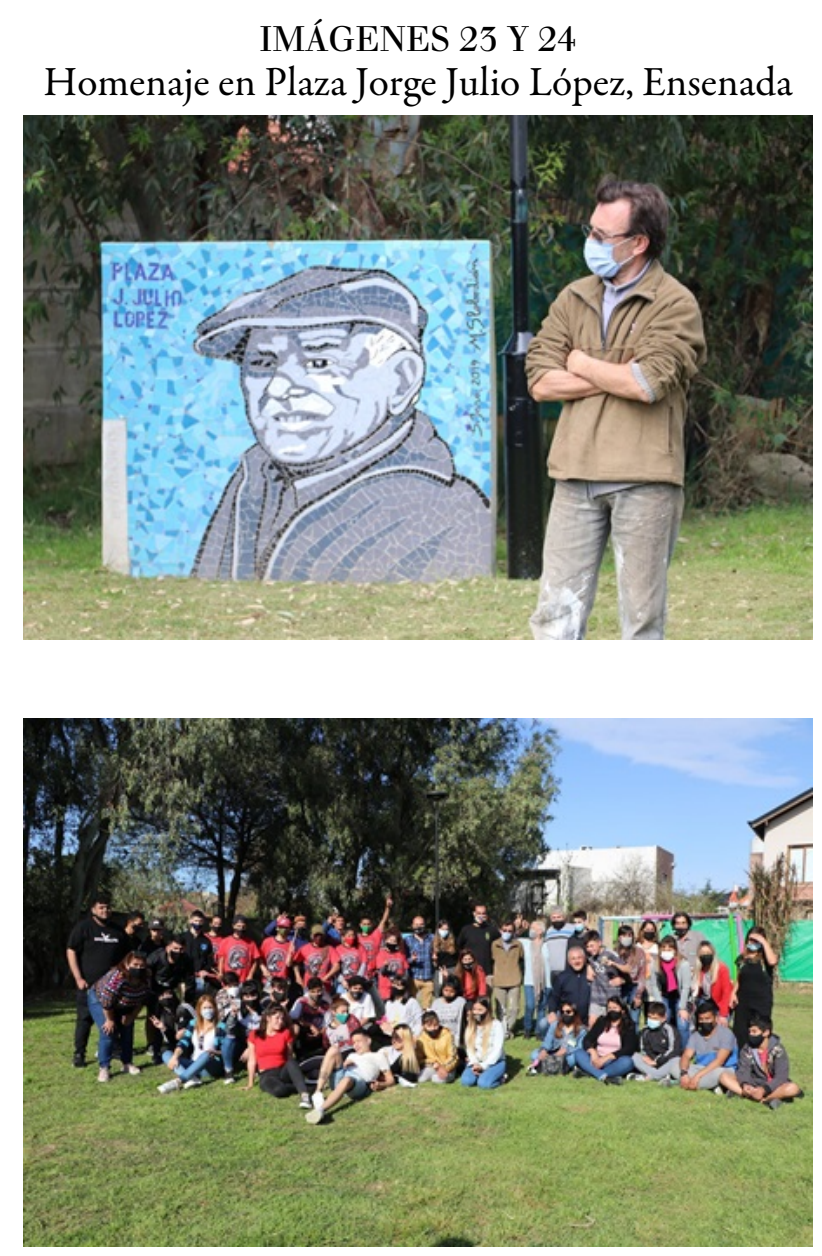

Fotografías recuperadas de: Prensa Ensenada, https://www.faceboo k.com/prensamunicipalidadensenada/posts/4914081151952784/

El día 27 de septiembre se realizó la Muestra (Des)apariciones de López en el Centro Cultural y Político AwkaChe. Esta exposición permaneció abierta al público desde las 10 hs. hasta las $17 \mathrm{hs}$ del mismo día, y contó con obras de Hugo Vidal, fotografías de Helen Zout, la serie fotográfica titulada La calle que habla de López, de Gabriela Hernández, y el Archivo AwkaChe de acciones por Julio López. La redacción del texto de presentación de la muestra estuvo a cargo de Magdalena Perez Balbi. El mismo cierra diciendo "Esta muestra, entonces, no es solo un compendio de imágenes o una documentación sobre activismo. A diferencia de otras efemérides de repercusión nacional, como el $24 \mathrm{M}$, el $8 \mathrm{M}$ o 3J, lo que podemos ver en estos 15 años de intervenciones por la segunda desaparición de López es la huella y la vigencia que tiene en la memoria local"2. 
IMÁGENES 25, 26 Y 27

Muestra (Des)apariciones de López en el Centro Cultural y Político AwkaChe
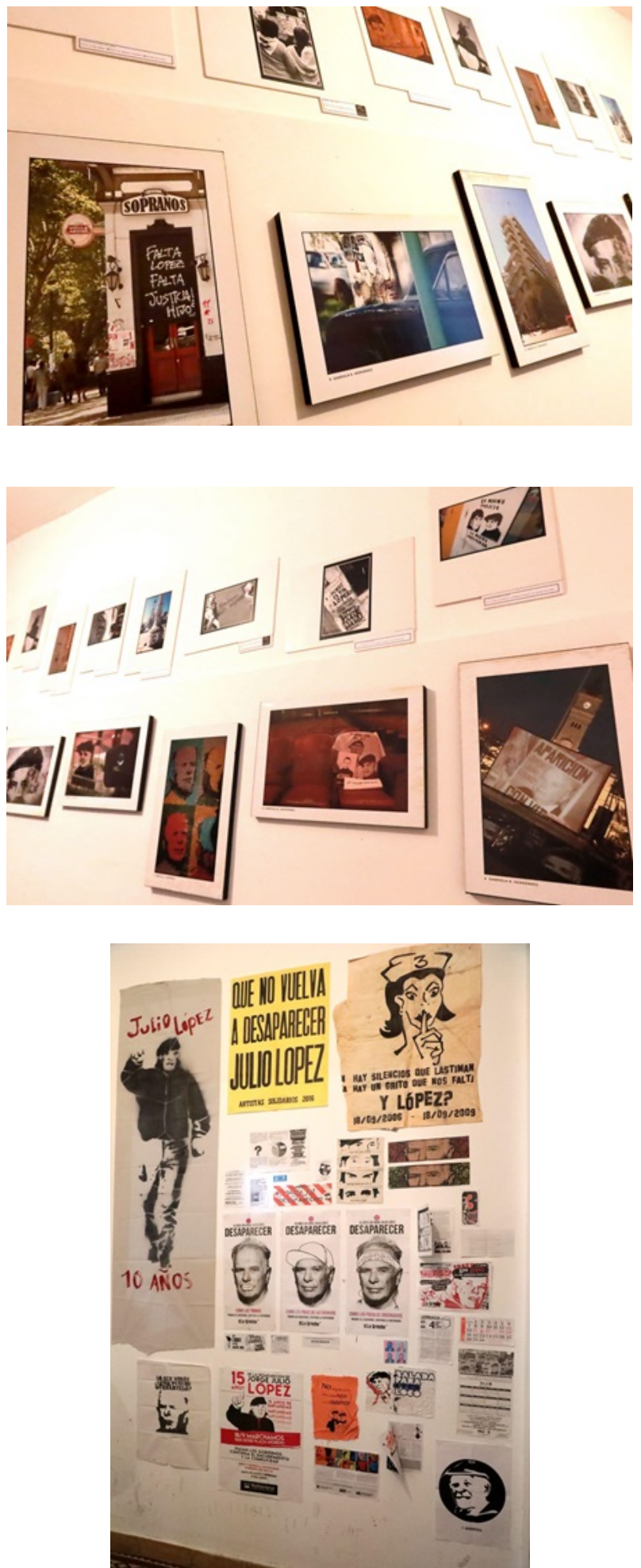

Fotografías: Gabriela B. Hernández (GbH Sur fotografía) 


\section{Notas}

1 Agradecemos a la fotógrafa Gabriela B. Hernández la gentileza de compartirnos sus fotografías. Su trabajo puede visitarse en su página de facebook: https://www.facebook.com/GabrielaHernandezFotografia

2 El texto completo puede leerse en:

https://www.facebook.com/1541895106043739/posts/3102275210005713/ 